\title{
Nonwoven Polymeric Fabrics Modified by Poly(Dimethylphosphazene)
}

\author{
Radka Kopecká*, Jiřri Př́íhoda and Milan Alberti \\ Department of Chemistry, Faculty of Science, Masaryk University Brno, The Czech Republic
}

Submission: February 02, 2021; Published: February 18, 2021

*Corresponding author: Radka Kopecká, Department of Chemistry, Faculty of Science, Masaryk University Brno, The Czech Republic

\section{Abstract}

This review presents poly(dimethylphosphazene) (PDMP), as the simplest representative of poly[(organo)phosphazenes], which was used as the additive into commercial polymer mixtures. This mixture was electrostatically spun. The formation and behaviours, such as wettability, of PDMP modified layers, were investigated.

Keywords: Phosphazene; Poly(dimethylphosphazene); Electrospinning; Nanofibers

\section{Introduction and Theory}

The effort to make new materials from already well-known compounds is the goal of many current scientists. The synthetic possibilities in polyphosphazenes chemistry has enabled the development of a wide range of matrixes with a variety of physical, chemical, and biological properties. Poly[(organo) phosphazenes] introduce a unique class of extremely versatile compounds with huge potential for various applications. Due to their high ability to be functionalized by a wide range of side groups, [1] they offer number of advantages, such as the completely degradable PN backbone, non-toxic degradation products, wettability affects, flame retardancy, etc. [2]. The aim of this review is to introduce poly(dimethylphosphazene) (PDMP), as the simplest representative of poly[(organo)phosphazenes] [3]. This compound is soluble in both polar and nonpolar solvents, which allows to create electrospan nonwoven textile. In electrospan nonwoven textile, small pores, having large surface area, are present. It enables its enhanced hydrophobic behaviour. Therefore, the effect of the PDMP mixed with chosen commercial polymers/copolymers with the impact on the final hydrophobic behaviour of the electrospan product has been investigated. New type of nanocomposite layers, containing a combination of organic and inorganic species, that can have both, the advantages of commercial polymers/copolymers e.g. hardness, good barrier properties, and other benefits of the additive (thermal stability and higher hydrophobicity), has been prepared. These properties could lead to their broader applications.

\section{Materials and Chemical Analysis}

PDMP was synthesized according to polycondensation method, [4] characterized by ${ }^{31} \mathrm{P}\left\{{ }^{1} \mathrm{H}\right\}$ NMR analysis with the chemical shift $\delta 30.6 \mathrm{ppm}$, ATR-FTIR analysis with the characteristic vibration band around $1200 \mathrm{~cm}^{-1}$. Typical values of average molecular weight (Mn) were around 40 000. PDMP presents only the melting transition at $145^{\circ} \mathrm{C}$ [4]. Polymers PA6 ( $\rho$ 1.10-1.14 g.cm ${ }^{-3}$, Tt 210-225 $\left.{ }^{\circ} \mathrm{C}, \mathrm{Tg} 47^{\circ} \mathrm{C}\right)$, PS ( $\rho 1.05$ g.cm ${ }^{-3}$, Tt $\left.240{ }^{\circ} \mathrm{C}, \mathrm{Tg} 95^{\circ} \mathrm{C}\right)$, copolymers SAN ( $\rho 1.08 \mathrm{~g} \mathrm{~cm}^{-3}$, Tt $185-285^{\circ} \mathrm{C}, \mathrm{Tg}$ $100-120^{\circ} \mathrm{C}$ ), ASA ( $\rho 1.76$ g.cm ${ }^{-3}$, Tt $210-270^{\circ} \mathrm{C}$, Tg $\left.85-115^{\circ} \mathrm{C}\right)$. PA6 was dissolved in trifluoroacetic acid (TFA) to create $12 \mathrm{wt} \%$ PA6 solution. PS, SAN and ASA were dissolved in dimethylformamide (DMF) to create $25 \mathrm{wt} \%$ PS, SAN or ASA solutions. Each solution was divided into two parts. The first portion was span on its own, to the second portion $10 \mathrm{wt} \%$ PDMP was added [5]. TFA was used in the commercial quality, DMF were purified by distillation (b.p. $153^{\circ} \mathrm{C}$ ). The electrospinning process was carried out using Elmarco Nanospider ${ }^{\mathrm{TM}}$ NSLAB 500 pilot plant unit, rod electrode (Figure 1).

The distance between electrodes was $170 \mathrm{~mm}$, the voltage between the electrodes $45 \mathrm{kV}$, current $0.001 \mathrm{~mA}$. Twenty drops of a spinning mixture of approximately equal volume was using, each drop was fiberized for $5 \mathrm{~min}$. PP foil was used as a covering foil for the collector $[6,7]$. The chemical composition of nanofibers was determined by physicochemical methods, e.g. ${ }^{31} \mathrm{P}\left\{{ }^{1} \mathrm{H}\right\}$ NMR spectroscopy (Bruker AVANCE DRX 300 instrument at frequencies 
${ }^{31} \mathrm{P}$ : $202.46 \mathrm{MHz}$ with $85 \%$ solution of $\mathrm{H}_{3} \mathrm{PO}_{4}$ (external standard). The spectra were measured in the coaxial NMR cuvette system [8]. ATR-FTIR spectroscopy (Bruker Vertex 80V spectrometer with attenuation total reflection mode using a diamond crystal, spectral range calibrated from 4000 to $600 \mathrm{~cm}^{-1}$ ). Bruker OPUS software was used for spectra evaluation.) [9]. The surface structure was described by SEM-EDX analysis (Tescan MIRA3, samples covered by $30 \mathrm{~nm}$ gold layer, measuring depth regime with $15 \mathrm{kV}$, working distance $10 \mathrm{~mm}, 20.000 \mathrm{x}$ magnification. Image J software was used for snaps evaluation) [10]. The nanofibers hydrophobic behaviour was described by contact angle analysis (Digidrop contact angle measuring device from DataPhysics; testing liquid $1 \mu \mathrm{l}$ distilled water, the water contact angle value was determined from the droplet image by tangent method, using software SCA 20) $[11,12]$.

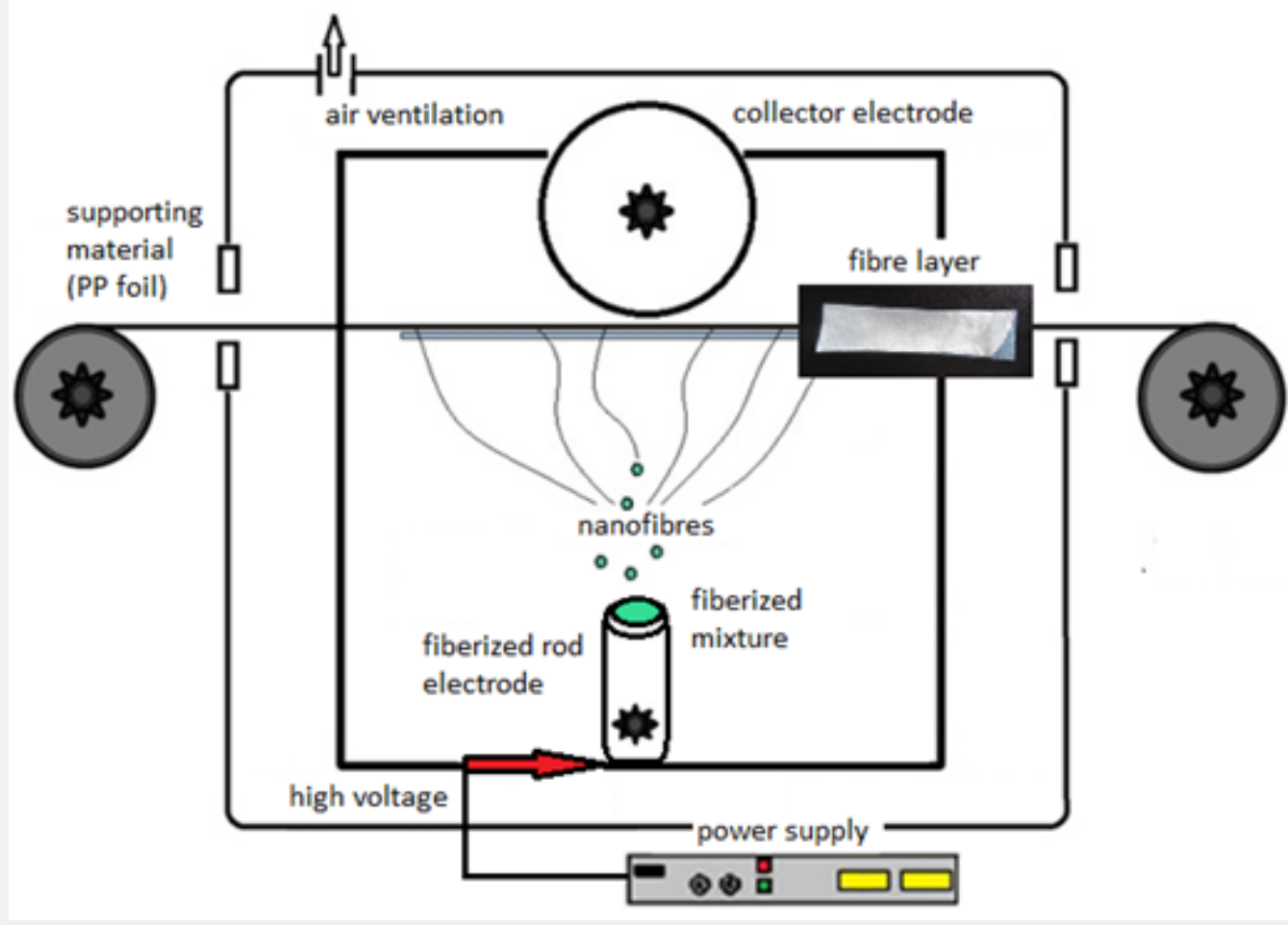

Figure 1: Scheme of Elmarco Nanospider ${ }^{\mathrm{TM}}$ NSLAB 500 system.

\section{Experimental Results and Discussion}

The first spinning attempts to gain fibres, made only from PDMP, were unsuccessful, only electrospray was observed. As no fibres were formed, PDMP was used as an additive into selected commercial polymers/copolymers (PA6, PS, SAN, ASA). These commercial polymers together with PDMP were electrospan successfully. The scheme of used Elmarco Nanospider ${ }^{\mathrm{TM}}$ NSLAB 500 system is depicted on (Figure 1). The presence of PDMP in the nanolayers was confirmed either by ${ }^{31} \mathrm{P}\left\{{ }^{1} \mathrm{H}\right\}$ NMR measured from redissolved fibres (singlet with chemical shift around $\delta$ $30.6 \mathrm{ppm}$ ), or by ATR-FTIR (Figure 2), three vibration spectra were compared - for pure PDMP (green line), commercial polymer/copolymer (blue line), and fiber layer containing PDMP + commercial polymer/copolymer (red line). Characteristic vibration bands of PN group around $1210 \mathrm{~cm}^{-1}$ (yellow frame) were observed for samples containing PDMP + PS, ASA and SAN.
These vibrations were overlapped by the spectra measured from samples containing PA6 and PDMP + PA6. SEM-EDX analysis detected the most abundant atoms (i.e. N, P, O, C) in the samples. The phosphorus atoms, coming from PDMP, were depicted using yellow colour in SEM-EDX image (Figure 3, the example of PA6+PDMP sample).

The homogeneity and values of fibres average width formed only from organic polymers (PA6, PS, ASA, SAN) were compared with values taken from fibres containing PDMP and the corresponding organic polymer. The samples based on electrospan PA6, PS, SAN formed relatively homogenous nanofiber layers, whereas ASA showed many irregularities and drops formation as the result of electrospraying process (Figure 4). This was probably caused by inappropriate concentration of the fiberized mixture. The presence of PMDP in mixtures of polymer solutions affected the fiber width. The fiber widths increase 
in the case of fibres consisting of PA6 or PS + PDMP to around 1.13 micron and the fiber width in fibres containing SAN + PDMP increases about 0.09 micron. The fiber widths for fibres from ASA cannot be described because of many irregularities. The presence of PDMP also influenced the values of water contact angles. It follows from Figure 4, the addition of PDMP into originally hydrophobic polymers PA6 and SAN (water contact angle less than $90^{\circ}$ ) reduces their hydrophilicity, whereas the addition of PDMP into the originally hydrophobic polymers PS, ASA (water contact angles higher than $90^{\circ}$ ) increases their hydrophobicity. The graphical comparison of wettability behaviour of fiber layers is presented on Figure 5.
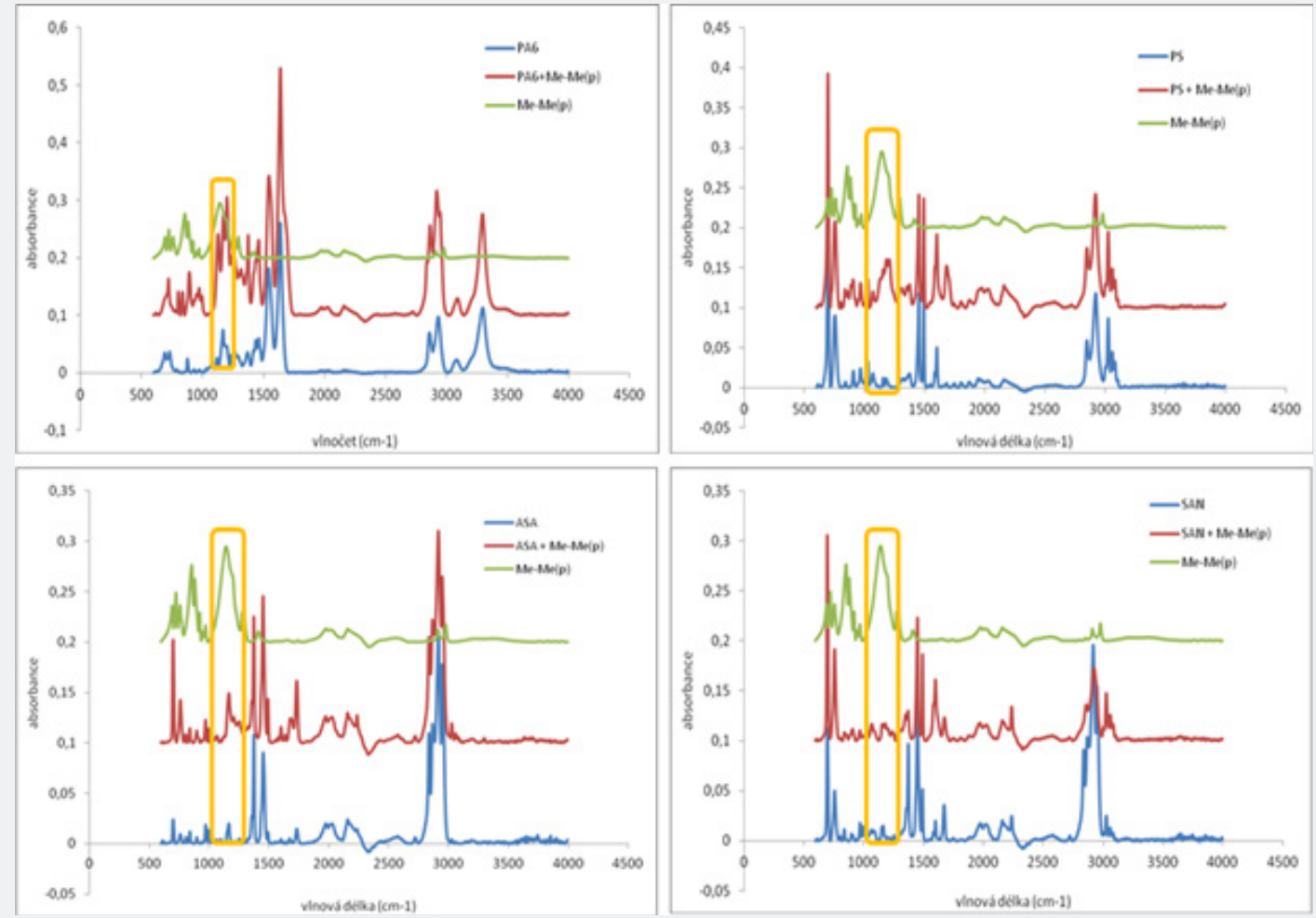

Figure 2: ATR-FTIR fiber analysis.

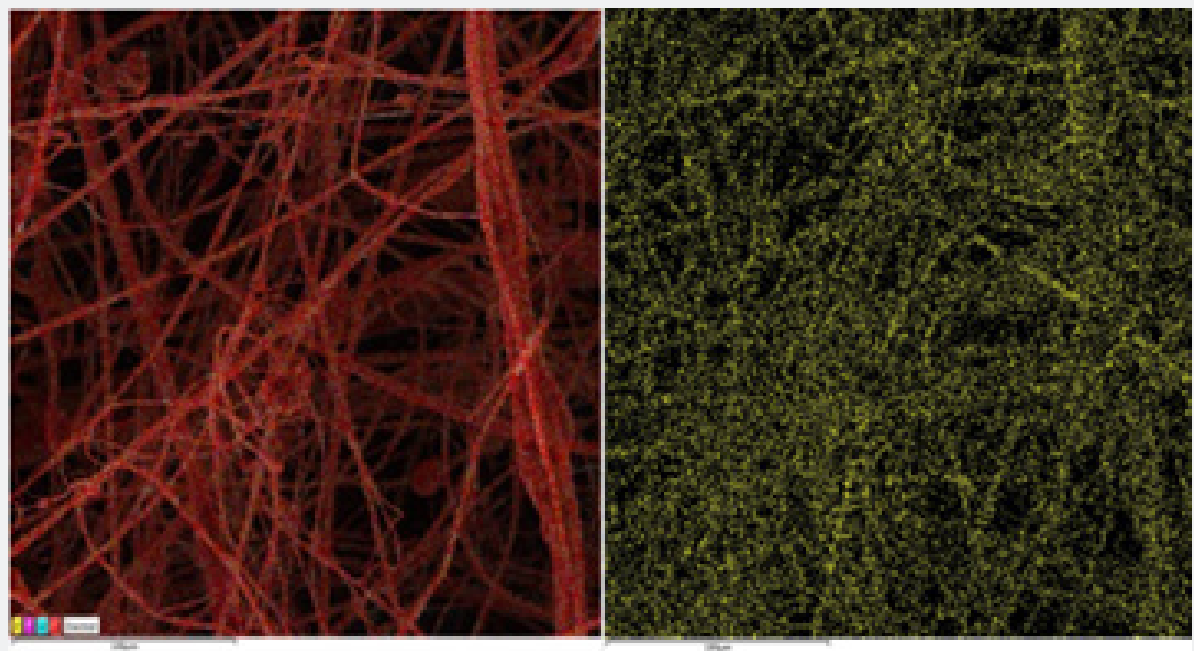

Figure 3: SEM-EDX fiber analysis. 

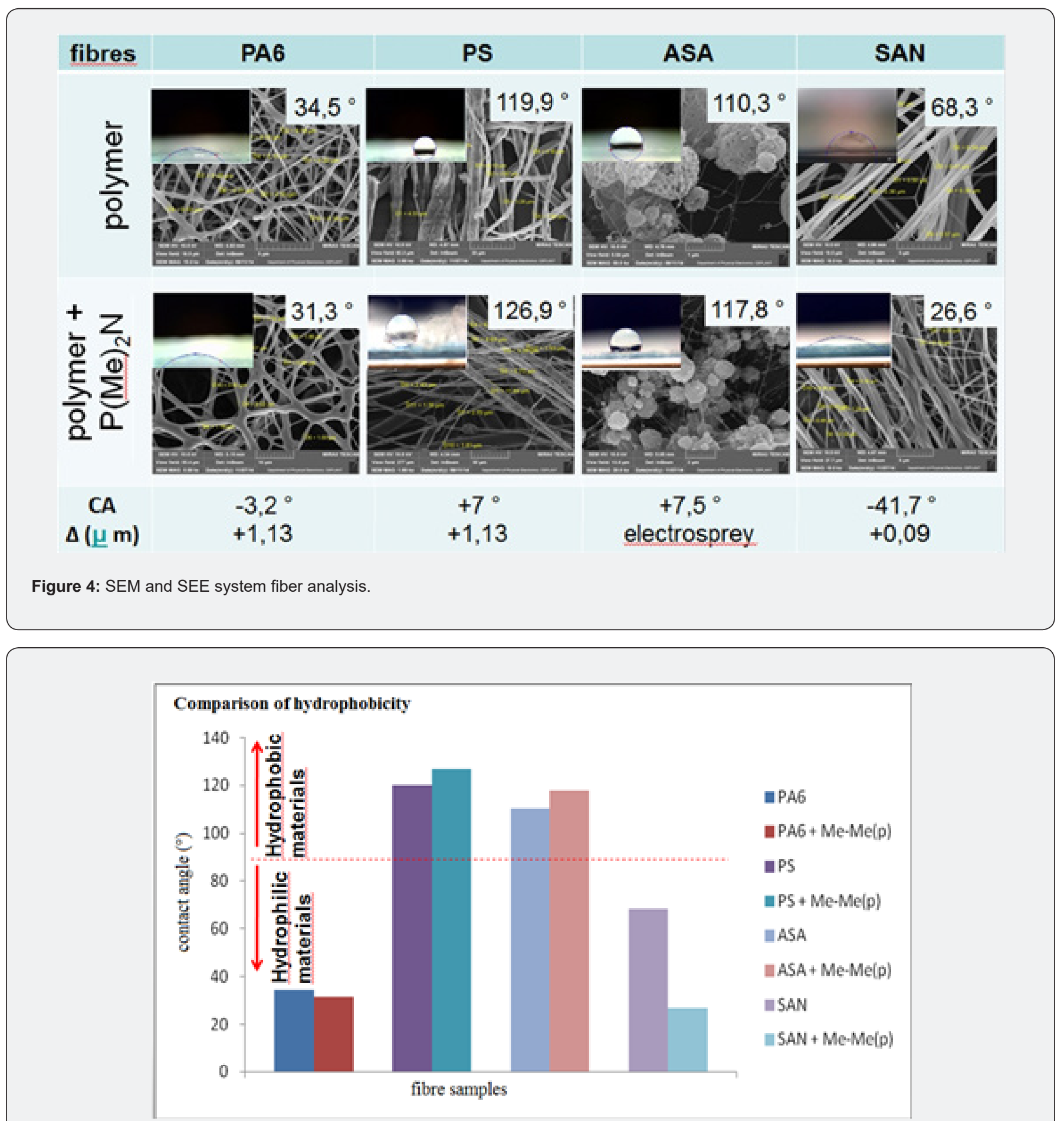

Figure 5: Wettability comparison.

\section{Conclusion}

Phosphazenes introduce a family of originally inorganic molecular hybrid monomers/oligomers/polymers with truly diverse properties due to the array of organic/ inorganic substituents. During the last decades, much attention has also been paid to the problem of commercial polymer modification. Due to the possibility of large fluctuations in the properties (e. q. flame retardancy, thermal stability, wettability, biocompatibility, etc.) of phosphazene derivatives, the commercial polymers can be modified not only by their substitution reaction but also by adding phosphazene derivatives. All these facts provide 
an increased possibility for their application. This review presents PDMP as the simplest representative from the row of poly(alkylphosphazenes), that can be mixed and formed with commercial polymers. Although, PDMP cannot successfully fiberized on its own, it was used as an additive into commercially available polymers and the nanofiber layers were possible to create by electrospinning technique. The PDMP presence in the fiber layers was confirmed by ${ }^{31} \mathrm{P}\left\{{ }^{1} \mathrm{H}\right\}$ NMR, and ATR-FTIR. The additive homogeneity spreading was confirmed by SEM-EDX. It was found that PDMP has an influence on the hydrophobic behaviour of nanolayers, whereas the major role in their properties still plays the used commercial polymer. In the case of originally hydrophilic polymer/copolymer (PS, ASA) overall hydrophobicity of nanolayers with PDMP decrease, whereas in case of commercial originally hydrophobic polymer (PA6, SAN) the overall hydrophobicity slightly grows. This review mainly presents the possibilities of forming organo phosphazenes and commercial polymer mixtures, their forming into electrostatically spun fiber layers and the possibility of modifying the commercial polymers properties with biodegradable additives.

\section{Acknowledgement}

I would like to express my gratitude to Prof. Patty Wisian Neilson for the chance to gain immense knowledge in polymer phosphazene chemistry, such as PDMP.

\section{References}

1. Wisian NP,Allcock HR, Kenneth JW (1993) Inorganic and organometallic polymers II: advanced materials and intermediates: developed from a symposium sponsored by the Division of Polymer Chemistry. Inc.,at the $205^{\text {th }}$ National Meeting of the American Chemical Society, USA.

2. De Jaeger R, Mario G (1998) Poly(organophosphazene)s and related compounds: Synthesis, properties and applications. Progress in Polymer Science 23(2): 179-276.

3. Gallazzi MC, Montoneri E, Savarino P, Bianchi F, Di Landro L (1993) Polydimethyl phosphazene as a material for new organo-inorganic separation membranes. Journal of Materials Science Letters 12(6): 436-438.

4. Neilson RH, Wisian N (1985) Polyphosphazene compounds and method of preparation.

5. Bačovská R, Patty WN, Milan A, Jiří P, Lucie Z, et al. (2016) Phenylmethyl phosphazene derivatives for preparation and modification of hydrophobic properties of polymeric nonwoven textiles 100: 53-63.

6. JIRSÁK O, Filip S, David L, Václav K, Lenka M, Jiří C (2004) Process for the production of nanofibers from a polymer solution by electrospinning and apparatus for carrying out the process. Technical University of Liberec, Czechia.

7. Doshi J, Darrell HR (1995) Electrospinning process and applications of electrospun fibers. Journal of Electrostatics 35(2-3): 151-160.

8. (2016) Nuclear Magnetic Resonance (NMR). Bruker corporation, USA.

9. (2016) Bruker Corporation. Infrared and Raman Spectroscopy Software.

10. Mira ML (2016) Tescan. Tescan orsay holding.

11. (2008) Advex Instruments - See system.

12. (2013) Adhesives-Wettability-Determination by measurement of contact angle and surface free energy of solid surface.

Your next submission with Juniper Publishers will reach you the below assets

- Quality Editorial service

- Swift Peer Review

- Reprints availability

- E-prints Service

- Manuscript Podcast for convenient understanding

- Global attainment for your research

- Manuscript accessibility in different formats

( Pdf, E-pub, Full Text, Audio)

- Unceasing customer service

Track the below URL for one-step submission

https://juniperpublishers.com/online-submission.php 